\title{
The Impact of Compact Urban Management on Environmental Quality: Evidence from Chinese Cities
}

\author{
Like Yuan \\ Chinese Academy of Science and Technology for Development, Beijing, P.R. China \\ yuanlike@126.com
}

\begin{abstract}
Keywords: Compact urban management; Environmental quality; Chinese cities
Abstract. Periods of decentralization had exerted a tremendous pressure on the cities environmentsustainability. The compact city concept was seen as an approach that could end "the evil of urban sprawl". This paper uses GDP density as the index of compact city to examine the determinants of environment sustainability in China using a spatial econometric framework. The results confirm that pollution is positively affected by pollution in nearby cities. Investigations of the determinants of environment sustainability that ignore this spatial relationship are likely to be mis-specified. Considering the spatial effect, the statistical significant inverted U-shaped curves are found in the estimation of the impact of GDP density on the pollution. It illustrates that city's pollution will be decreased with the compact urban development.
\end{abstract}

\section{Introduction}

The concept of the compact city is a key urban management strategy to limit suburban sprawl and to obtain a more sustainable urban development. Urban sprawl has been shown to be highly inefficient, especially in the provision of services and infrastructure by local governments. In China, Beijing is a typical case.

There is a large literature that highlights the role of compact forms of urbanization as a basis for a more sustainable urban development (United Nations, 1993; European Commission, 2011). Many reports suggest that a compact city reduces energy, makes investments in public infrastructure more viable, reduces land usage thereby preserving agricultural land and natural areas, and is positively associated with social diversity and with cultural and economic development (Elkin et al., 1991; European Commission, 2011). However, there is also a considerable group of researchers who argue that the case of the compact city is not proven and that there is evidence which suggests that the claims of the supporters do not reflect the hard reality of economic demands, environmental sustainability and social expectations (Nabielek, 2012). The empirical example of Taiwan shows the density and the process of intensification not only positively influences economic sustainability but also negatively influence environmental and social sustainability (Lin and Yang, 2006). However, the few studies that examine the effect of externality in the analysis of determinants with a spatial econometric approach. This paper contributes to the literature is this way.

The paper is organized as follows. Section 2 examines a number of spatial econometric issues and the data source in this paper. Section 3 adopts the spatial econometric approach to test the spatially adapted model at the China municipal cities level, and section 4 concludes the paper.

\section{Methodology and Data}

Following Gert de Roo (2000), the relationship between the compact city and the environmental is for more than one reason controversial. The compact urban development will mostly likely have a negative effect on the quality of the environmental. Refer to the Environmental Kuznets Curves; we posit a relationship between the logarithm of cities' emissions per capita, the logarithm of GDP density and their squared value. The estimation equation is given by:

$\log (E)=\alpha_{1}+\beta_{1} \log ($ compact city $)+\beta_{2}[\log (\text { compact city })]^{\wedge} 2+e$ 
Where $\mathrm{E}$ is either log of per capita waste water, $\mathrm{SO}_{2}$ or Soot emissions in cities, compact city is measured by either GDP per $\mathrm{Km}^{2}$ municipal district. To allow for the U shaped curves, I include the log compact city and the square of the log of compact city.

It is well known that regional data cannot be regarded as independently generated because of the presence of spatial similarities among neighboring regions (Anselin et al., 1996). None growth of the country, neither economic nor environmental (sustainable) can exists without any impact of regions situated closely. Spatial econometrics recognizes that units might be correlated across space (Anselin, 1988). As indicated above, estimating a linear model with least squares in the presence of spatial correlation would yield biased estimates. The spatial lag model for compact urban development and environment sustainability is given by:

$$
\log (E)=\alpha_{1}+\beta_{1} \log (\text { compact city })+\beta_{2}[\log (\text { compact city })]^{\wedge} 2+\rho W \log (E)+\mu
$$

The variable gathered by the term $W \log (E)$ is therefore the spatial lag for the pollution. We interpret an influence of this variable on the endogenous as evidence of intercity spillovers of the pollution. The second way to incorporate spatial autocorrelation into the model is to specify a spatial

process for the disturbance term.

$$
\begin{aligned}
& \log (E)=\alpha_{1}+\beta_{1} \log (\text { compact city })+\beta_{2}[\log (\text { compact city })]^{\wedge} 2+\mu \\
& \mu=\lambda W \mu+\varepsilon)
\end{aligned}
$$

All the Dates were taken from the China City Statistical Yearbook 2010. The number of cities is 284; some cities are not chosen in this paper for the missing values.

The main dependent variables used in this paper are three pollutants: Waste Water emissions, $\mathrm{SO}_{2}$ emissions and SOOT emission. The three emissions are the main pollutions in China. As such, they clearly capture a measure of environmental quality. Based on the previous research (Burton, 2002; Matsumoto, 2012), we use Secondary and tertiary industry GDP per km ${ }^{2}$ municipal district as the proxies of compact city. Table I presents the explanatory variables included in the model, and report the descriptive statistics. In order to avoid sharp fluctuations of the data, the paper takes the logarithm form for all the variables.

Table 1: Summary statistics

\begin{tabular}{llllll}
\hline Variable & Definition & mean & Min & Max & SD \\
\hline WATER & $\begin{array}{l}\text { Industrial waste water discharged per ten } \\
\text { thousands population }\end{array}$ & 5.120 & 3.606 & 6.295 & 0.434 \\
$\mathrm{SO}_{2}$ & $\begin{array}{l}\text { Industrial } \mathrm{SO}_{2} \text { emission per ten thousands } \\
\text { population }\end{array}$ & 2.058 & -0.677 & 3.276 & 0.490 \\
$\mathrm{SOOT}$ & $\begin{array}{l}\text { Industrial soot emission per ten thousands } \\
\text { population }\end{array}$ & 1.549 & -0.237 & 2.984 & 0.476 \\
GDP & $\begin{array}{l}\text { Secondary and tertiary industry GDP per Km } \\
\text { municipal district }\end{array}$ & 3.386 & 1.393 & 4.762 & 0.620 \\
\hline
\end{tabular}

\section{Empirical Estimation and Results}

The equation is estimated by OLS for each pollutant in turn and the results are presented in Table 2 . The elasticity of emissions with respect to economic index of compact city is positive and strongly significant. This illustrate that there are a monotonic relationship between compact city and Water \& $\mathrm{SO}_{2}$ emissions per capita. The models than include a second-order effect for compact city indicate that, on average, there is evidence of an inverted-U relationship between SOOT emissions and compact urban development. The turn point is 3.579; it means that form this level of compact urban development provides to decrease of SOOT emissions. 
Table 2: Results of OLS model

\begin{tabular}{llll}
\hline Independent Variables & WATER & SO2 & SOOT \\
\hline Constant & $3.433^{* * *}$ & 0.641 & 0.043 \\
& $(0.536)$ & $(0.632)$ & $(0.635)$ \\
GDP DENSITY & $0.752^{* *}$ & $0.713^{*}$ & $0.866^{* *}$ \\
\hline & $(0.332)$ & $(0.391)$ & $(0.393)$ \\
GDP DENSITY2 & -0.073 & -0.084 & $-0.121^{* *}$ \\
& $(0.050)$ & $(0.059)$ & $(0.060)$ \\
R-squared & 0.155 & 0.048 & 0.024 \\
F-statistic & $25.858^{* * *}$ & $7.138^{* * *}$ & $3.464^{* *}$ \\
Log likelihood & -141.927 & -189.117 & -190.326 \\
Akaike info criterion & 289.854 & 384.234 & 386.651 \\
Moran's I & $6.501 * * *$ & $6.164 * * *$ & $7.681^{* * *}$ \\
LM-lag & $12.473^{* * *}$ & $37.338^{* * *}$ & $50.349 * * *$ \\
Robust LM-lag & 1.830 & $6.352^{* *}$ & 2.686 \\
LM-error & $39.315^{* * *}$ & $35.252^{* * *}$ & $55.268^{* * * *}$ \\
Robust LM-error & $28.672^{* * *}$ & $4.266^{* *}$ & $7.604 * * *$ \\
\hline
\end{tabular}

Notes: Observations 284 regions; Robust standard errors are given in parentheses; ${ }^{*}$ significant at the $10 \%$ level; **significant at the $5 \%$ level; $* * *$ significant at the $1 \%$ level.

With a deeper relation to our goal is the fact that spatial autocorrelation in the residuals is clearly discovered, as shown in the lower section of Table 3.The LM-LAG clearly reject the null of absence of spatial autocorrelation at the $1 \%$ level of significance, indicating misspecification of the model, so that some kind of externalities across regions may take place in the explanation of the regional economy. We followed Anselin's (1996) recommendation and used the Lagrange Multipliers to decide on a spatial lag or spatial error respecification. Here, the spatial lag model is the preferred respecification. When estimated by ML, the explanatory power of the regressions is substantially and significantly increased and the significant value of the Likelihood Ratio tests in spatial lag dependence point to the statistical adequacy of the estimation of the spatial models. Location and distance are important forces of spatial spillovers of air pollutions, the coefficients on the spatial lag and spatial error terms are highly significant. In $\mathrm{SO}_{2}$ spatial lag model, the spatial lag term of $\mathrm{WlogSO}_{2}$ reflects the spatial dependence inherent in the sample data, measuring the average influence on observations by their neighboring observations. In Water and SOOT spatial error model, the coefficient on the spatially correlated errors Lambda is added as an additional indicator. It has a positive effect.

Table 3: Results of spatial econometric model

\begin{tabular}{llll}
\hline Independent Variables & WATER & SO2 & SOOT \\
\hline Constant & $2.568^{* * *}$ & -0.417 & -0.661 \\
& $(0.536)$ & $(0.583)$ & $(0.626)$ \\
GDP DENSITY & $1.317^{* * *}$ & $0.821^{* *}$ & $1.283^{* * *}$ \\
GDP DENSITY2 & $(0.323)$ & $(0.359)$ & $(0.379)$ \\
$\rho$ & $-0.162^{* * *}$ & $-0.104 *$ & $-0.183^{* * *}$ \\
& $(0.048)$ & $(0.055)$ & $(0.057)$ \\
$\lambda$ & & $0.461 * * *$ & $0.664 * * *$ \\
& & $(0.054)$ & $(0.051)$ \\
R-squared & $0.677 * * *$ & & 0.228 \\
Log likelihood & $(0.050)$ & & -163.897 \\
Akaike info criterion & 0.314 & 0.193 & 344.762 \\
Likelihood ratio test & -119.360 & -168.734 & $52.857 * * *$ \\
\hline
\end{tabular}

Considering the spatial effect, it is clear that the environmental impact indicator is an inverted Ushaped function between pollution and economic index of compact city. The turning point of compact city for Waste Water emission, $\mathrm{SO}_{2}$ emission and SOOT emission is 4.065, 3.947 and 3.505 (logarithm value) respectively. It means that from these levels of compact city, the 
environment degradation decrease. Many cities in China have beyond the turn point. It illustrate that the relationship between the pollution and compact urban development of these cities is on the stage of benign circulation.

\section{Conclusion}

The main purpose of this paper has been to highlight the relationship between compact urban development and environmental sustainability. Results obtained are made robust to possible spatial dependence or correlation across observations through the use of spatial econometrics tools. After having detected the presence of spatial effects in the model, the study find there are an inverted Ushaped curve of the impact of GDP density on the environmental quality. It implies the cities' environment sustainability will be improved gradually with the economic development of compact city.

\section{References}

[1]. Anselin, L. 1988. Spatial Econometrics: Methods and Models. Dordrecht.

[2]. Anselin, L., Bera, A., Florax, R. J. G. M., and Yoon, M. 1996. Simple diagnostic tests for spatial dependence. In: Regional Science and Urban Economics, 26, 77-104.

[3]. Burton E. 2002. Measuring urban compactness in UK towns and cities, Environment and Planning B: Planning and Design, 29: 219-250.

[4]. de Roo G. 2000. Environmental conflicts in compact cities: complexity, decision-making, and policy approaches, Environment and Planning B: Planning and Design, 27(1), 151 - 162

[5]. Elkin, T., McLaren, D. and Hillman, M. 1991. Reviving the City: towards sustainable urban development, Friends of the Earth, London

[6]. European Commission, Directorate General for Regional Policy. 2011. Cities of tomorrow Challenges, visions, ways forward. Luxembourg: Publications Office of the European Union.

[7]. Jen-Jia Lin and An-Tsei Yang. 2006. Does the compact city paradigm foster sustainability? An empirical study in Taiwan, Environment and Planning B: Planning and Design, 33(3) 365-380

[8]. Kersten Nabielek. 2012. The compact city: planning strategies, recent development and future prospects in the Netherlands, AESOP 26th Annual Congress, July, METU, Ankara.

[9]. Tadashi Matsumoto. 2012. Compact city policies: a comparative assessment applying a new definition of "urban", Presentation at the RSA European Conference, Delft, the Netherlands

[10]. United Nations, 1993. Earth Summit Agenda 21: The UN Programme of Action from Rio. New York: United Nations 